\title{
Prinsip pembelajaran mentalis dalam pengajaran dan pembelajaran teks Kesusasteraan Melayu Sekolah Menengah
}

\author{
${ }^{1}$ Cynthia Layah Geraman, ${ }^{2}$ Azhar Wahid \\ ${ }^{1}$ Sekolah Menengah Kebangsaan Lundu, Sarawak, \\ ${ }^{2}$ Fakulti Bahasa dan Komunikasi, Universiti Pendidikan Sultan Idris \\ 1'cynthialayah88@gmail.com, 2azhar@fbk.upsi.edu.my
}

DOI: https://doi.org/10.37134/peradaban.vol14.3.2019

\begin{abstract}
ABSTRAK
Kajian ini bertujuan untuk meneliti peranan prinsip pembelajaran mentalis dalam pengajaran dan pembelajaran teks Kesusasteraan Melayu sekolah menengah. Kajian dijalankan secara kualititatif di tiga buah sekolah menengah di sekitar Kuching, Sarawak, melibatkan kaedah soal selidik. Data dianalisis menggunakan perisian kualititatif skala likert dan juga Cohen's Kappa. Hasil kajian menunjukkan bahawa prinsip pembelajaran mentalis ini memberi kesan dalam pengajaran dan pembelajaran guru yang mengajar Kesusasteraan Melayu malah dapat mempengaruhi karakter pelajar agar berfikir secara kritis. Dapatan kajian mendapati bahawa pelajar Kesusasteraan Melayu dapat memahami perkara yang dipelajari oleh mereka semasa pembelajaran di dalam kelas dengan mengaplikasikan prinsip pembelajaran mentalis dalam Kesusasteraan Melayu. Implikasi kajian ini adalah penting untuk mengetahui sejauh mana prinsip pembelajaran mentalis ini dapat mempengaruhi pelajar untuk mempelajari Kesusasteraan Melayu malah memberi gambaran akan kepentingan dalam mempelajari Kesusasteraan Melayu.
\end{abstract}

Kata kunci: Prinsip Pembelajaran, Teks Kesusasteraan Melayu, sekolah menangah

\begin{abstract}
This study aims to examine the role of the mental learning principles in the teaching and learning of Malay Literature secondary school textbooks. The study was conducted qualitatively at three secondary schools around Kuching, Sarawak, involving questionnaire methods. Data were analyzed using likert-scale qualitative software as well as Cohen's Kappa. The results showed that the principle of this mentalist affect the teaching and learning of Malay teachers can even affect the character of students to think critically. The study found that students of Malay Literature can understand what they learn in the classroom while learning to apply the principles of learning mentalist in Malay Literature. An important implication of this study is to determine the extent of the mental learning principles can influence the students to learn Malay and even give importance in the study of Malay Literature.
\end{abstract}

Keywords: Principles Learning, Malay Literatute Texts, secondary school

\section{PENGENALAN}

Bidang pengajaran Kesusasteraan Melayu merupakan suatu bidang tugas amali yang kompleks dan multi-disiplin sifatnya. Pelbagai pendekatan digunakan untuk pengajaran mata pelajaran Kesusasteraan Melayu dalam bilik darjah bagi menarik minat para pelajar agar mereka dapat menghayati dan mempunyai minat yang mendalam dalam Kesusasteraan Melayu. Penghayatan kesusasteraan penting kerana karya sastera boleh dijadikan alat untuk membangunkan diri manusia seperti pembangunan daya intelek, perasaan peka terhadap masyarakat dan rasa keagamaan. Pendidikan di Malaysia adalah suatu usaha berterusan ke arah memperkembangkan lagi potensi individu secara menyeluruh dan bersepadu untuk mewujudkan insan yang seimbang dan harmoni dari segi intelek, rohani, emosi dan jasmani. 
Terdapat juga definisi teori yang dikemukakan oleh para sarjana dan pengkaji Melayu di Malaysia. Antara pengkaji Melayu tersebut ialah Ramli Isin (1997) dalam buku Teori dan Kritikan Sastera Barat dan Malaysia telah menjelaskan bahawa teori adalah gagasan tentang definisi, konsep, prinsip, kriteria dan saranan yang memperjelaskan sesuatu objek. Teori yang diaplikasikan oleh pengkaji dalam mata pelajaran Kesusasteraan Melayu ialah teori Mentalis.

Tujuan kajian ini dijalankan adalah untuk menganalisis penggunaan prinsip pembelajaran mentalis berdasarkan teks novel Kesusasteraan Melayu Tingkatan 6 dan Tingkatan 4 dalam memberi kefahaman dan penghayatan pelajar terhadap karya sastera. Dalam pengujian ini, pengkaji melibatkan penggunaan beberapa orang pelajar dari kelas-kelas Kesusasteraan Melayu di sekolah bagi mendapatkan data yang diperlukan. Secara tidak langsung, hal ini juga berupaya membuktikan bahawa subjek

Kesusasteraan Melayu juga relevan menggunakan corak pembelajaran berasaskan Prinsip-prinsip Pembelajaran sebagaimana kaedah pembelajaran ini diterapkan dalam mata pelajaran yang lain. Pengaplikasian Teori Mentalis berdasarkan novel teks Kesusasteraan Melayu dalam pembelajaran Kesusasteraan Melayu berupaya melahirkan generasi perintis negara yang mempunyai ilmu sastera yang tinggi, malah juga mempunyai etika dan akhlak yang seimbang. Keseimbangan dari segi keperluan intelek, emosi, rohani dan jasmani dalam masyarakat membantu dalam menjana kemajuan pembangunan dan kestabilan negara.

\section{LATAR BELAKANG}

Teori Mentalis merupakan antara teori yang berada dalam kumpulan teori Pemerolehan Bahasa. Pemerolehan merupakan suatu proses penguasaan bahasa yang dilakukan oleh pelajar secara natural sewaktu belajar. Latar belakang bagi teori Pemerolehan Bahasa, menurut Simanjuntak (1978:1) telah menganggap bahasa adalah satu struktur yang unik daripada bunyi-bunyi dan ucapan yang dipilih dan disusun secara sewenang-wenangnya untuk dipakai oleh sesuatu masyarakat untuk berhubung seperti yang akan dipelajari oleh pelajar. Bagi Vygotsky (1962) telah menerangkan bahawa bahasa bukanlah satu benda, tetapi satu proses, iaitu satu gerak yang berlaku terus-menerus daripada fikiran kepada kata dan daripada kata-kata kepada fikiran.

Selain itu, bagi latar belakang teori Mentalis pula merupakan teori psikologi koda kognitif berbeza dengan teori pembelajaran behaviurisme. Dalam buku Pengkaedahan Mengajar Bahasa (1995), George A. Miller yang merupakan seorang sarjana bagi teori Mentalis telah cuba untuk menggambarkan proses-proses mental yang dapat dilakukan oleh seseorang pendengar apabila menghadapi sesuatu pertuturan. Proses-proses tersebut ialah mendengar, memadamkan, menerima, mentafsirkan, memahami dan mempercayai. Dengan menggunakan proses tersebut maka pengkaji dapat mengenal pasti dan menganalisis prinsip pembelajaran mentalis kepada pelajar sama ada pelajar dapat mendengar, menerima, mentafsir dan memahami apa yang dipelajari mereka.

Kesusasteraan Melayu yang merupakan satu cabang ilmiah berupaya untuk membantu dalam menjana pembentukan modal insan dalam diri masyarakat, khususnya generasi perintis yang bakal menentukan baik buruk masa depan sesebuah bangsa dan negara. Bahkan sastera itu adalah sebahagian dari landasan utama identiti kebudayaan masyarakat yang juga menjadi satu wadah dalam memberi ilmu kepada masyarakat berkenaan nilai-nilai murni dan pengajaran agar mengenali jati diri, masyarakat, bangsa dan juga agama. Prinsip pembelajaran mentalis ini akan diaplikasikan kepada pelajar yang mengambil subjek Kesusasteraan Melayu dengan melihat dari segi kefahaman mereka berkaitan dengan Kesusasteraan Melayu.

\section{PERNYATAAN MASALAH}


Mata pelajaran Kesusasteraan Melayu sering dipandang ringan oleh mana-mana pihak berbanding mata pelajaran yang lain. Subjek ini tidak dianggap berdaya saing dan tidak mempunyai nilai komersial yang tinggi. Biarpun mata pelajaran Kesusasteraan Melayu hanyalah merupakan subjek elektif, para guru dan pentadbir tidak seharusnya memandang remeh pada subjek elektif seperti ini kerana bukan sahaja ia berupaya menyumbang kepada peningkatan peratusan kelulusan akademik para pelajar, malah juga turut memupuk nilai jati diri yang baik dalam diri pelajar sekiranya subjek ini disampaikan dan diterima dengan baik.

\section{OBJEKTIF KAJIAN}

Kajian ini adalah bertujuan:

1. Mengenal pasti prinsip pembelajaran mentalis dalam mata pelajaran Kesusasteraan Melayu.

2. Menganalisis penggunaan Skala Likert dan Cohen Kappa dalam prinsip pembelajaran mentalis pengajaran dan pembelajaran teks Kesusasteraan Melayu.

3. Mengkaji penggunaan Skala Likert dan Cohen Kappa dalam prinsip mentalis pengajaran dan pembelajaran teks Kesusasteraan Melayu.

\section{SOALAN KAJIAN}

1. Sejauh manakah pengaplikasian teori mentalis dalam Kesusasteraan Melayu.

2. Sejauh manakah keberkesanan pengaplikasian prinsip pembelajaran mentalis dalam teks Kesusasteraan Melayu.

3. Sejauhmanakah perkaitan prinsip teori mentalis ini dengan teks Kesusasteraan Melayu.

\section{KEPENTINGAN KAJIAN}

Kajian ini dapat memberi beberapa kepentingan terhadap pelbagai pihak untuk mencapai objektif tertentu. Antaranya ialah:

1. Hasil kajian ini boleh menjadi asas kepada pengajaran sastera untuk kegunaan guru-guru di semua sekolah menengah sebagai bahan bantu mengajar. Penggunaan teori dalam novel Saudagar Besar dari Kuala Lumpur dan Naratif Ogonshoto yang telah dikaji dijadikan sebagai pencetus idea kepada para guru Kesusasteraan Melayu untuk menghasilkan perisian yang menarik untuk tontonan pelajar. Perihal ini membolehkan pelajar lebih menghayati dan memahami sesuatu karya sastera yang terkandung dalam buku teks seterusnya lebih memudahkan para guru untuk memberi penerangan kepada pelajar secara lebih lanjut dalam sesi pengajaran dan pembelajaran.

2. Hasil kajian ini memberi idea kepada guru untuk merangka kaedah pengajaran dan pembelajaran yang lebih menarik, kreatif dan efektif untuk menarik minat dan motivasi pelajar dalam pembelajaran subjek Kesusasteraan Melayu. Dengan mengkaji teori mentalis dalam teks novel, para guru berupaya mengatur kaedah pengajaran dan pembelajaran dan yang bersesuaian bertepatan dengan masa PdP yang telah ditetapkan terutamanya dari segi pemerolehan bahasa. Hal ini kerana masa yang diuruskan dengan baik sangat diperlukan untuk guru menarik perhatian pelajar, memberi penerangan dan membuat penilaian terhadap pemahaman yang diperoleh daripada pelajar sewaktu sesi PdP. Justeru itu, pengurusan masa yang baik memberi peluang kepada para pendidik untuk merangka kaedah dan pendekatan yang boleh digunakan semasa PdP dengan berbantukan perisian yang dihasilkan dengan menarik dan kreatif. 


\section{BATASAN KAJIAN}

Kajian ini memberi tumpuan tentang prinsip pembelajaran teori mentalis yang akan dikaji dengan menggunakan teks Kesusasteraan Melayu antara pelajar Tingkatan 4 dan Tingkatan 6 iaitu menggunakan novel Saudagar Besar dari Kuala Lumpur dan Naratif Ogonshoto. Prinsip pembelajaran ini dipilih kerana masih belum lagi pengkaji yang mengkaji prinsip pembelajaran untuk Kesusasteraan Melayu. Hal ini demikian kerana prinsip pembelajaran ini lebih banyak digunakan untuk mengkaji dalam bidang Bahasa Melayu. Kajian ini menggunakan teori Mentalis yang merupakan cabang kepada teori Pemerolehan Bahasa. Oleh sebab itu, kajian ini dihadkan dengan menggunakan teori Mentalis dan juga instrument kajian yang digunakan ialah Kesahan Soal Selidik dan juga Cohen Kappa.

\section{METODOLOGI}

\section{Skop Kajian}

Proses yang akan dilakukan dengan menggunakan data sekunder dikutip menerusi kaedah kepustakaan, iaitu melalui pembacaan dua buah novel Kesusasteraan Melayu iaitu Saudagar Besar Dari Kuala Lumpur yang merupakan novel untuk Tingkatan 6 Rendah dan Naratif Ogonshoto untuk Tingkatan 5, buku ilmiah, jurnal, kertas kerja, prosiding seminar dan lain-lain dokumen yang berkaitan dengan penyelidikan yang dijalankan. Kajian kepustakaan dilakukan bertujuan untuk memperoleh maklumat yang mencukupi berkaitan teks Kesusasteraan Melayu sekolah menengah yang menggunakan teori Mentalis sama ada dari dalam negara atau luar negara.

\section{Kaedah Kajian}

Kajian ini dijalankan berdasarkan kaedah kualitatif dan kaedah penganalisian maklumat. Terdapat beberapa instrumen atau alat kajian yang digunakan untuk mendapatkan data iaitu borang soal selidik dan Cohen Kappa. Instrumen soal selidik dan Cohen Kappa dipilih adalah untuk mendapatkan data dalam kajian ini untuk mengukuhkan lagi dapatan kajian.

\section{Kaedah Kualitatif}

Peranan kaedah kualitatif yang menerangkan dan menyelidik kejadian atau peristiwa secara holistik kerana dengan menggunakan kaedah ini dapat mendedahkan sesuatu kejadian dengan menyeluruh supaya boleh mendapat semua maklumat secara menyeluruh. Kaedah kualitatif juga berperanan untuk melengkapkan teori atau melakukan hipotesis, kerana ia adalah suatu keterangan sementara dari satu fakta yang dapat diamati.

\section{Kaedah Penganalisisan Maklumat}

Pengkaji menggunakan borang soal selidik sebagai alat kajian kerana instrumen ini lebih efisien dan lebih praktikal sifatnya. Borang soal selidik yang disediakan mengandungi tiga bahagian iaitu Bahagian A, Bahagian B dan Bahagian C.

Penggunaan model skala likert adalah disebabkan kelebihan dan andaian-andaian yang menyatakan setiap individu mempunyai perbezaan tentang darjah persetujuan yang berbeza terhadap setiap pernyataan. Selain itu, kelebihan menggunakan skala ini disebabkan setiap pernyataan yang berbeza akan memberi darjah persetujuan yang berbeza juga. Darjah persetujuan responden yang bersikap positif mungkin lebih setuju berbanding dengan responden yang bersikap negatif. 
Bagi butiran setiap komponen latar belakang responden, pengkaji menggunakan skala bagi komponen soalan pada Bahagian A pula, pengkaji menggunakan skala nominal iaitu 'Ya' dan 'Tidak'. Skala likert iaitu setiap pemboleh ubah telah diberikan nilai angka atau nombor kod kepada kategori 1, 2, 3 pada bahagian B. Borang soal selidik yang disediakan untuk sampel pelajar mengandungi 22 soalan.
1. Setuju
2. Tidak setuju
3. Amat tidak setuju

\section{Kesahan Soal Selidik}

Menurut Hammereersley (1990) dalam Miles dan Hubberman (1994), kesahan dalam penyelidikan kualitatif telah ditakrifkan kepada sejauh mana tepatnya satu-satu gambaran yang diperlihalkan yang mewakili tajuk kajian yang telah dikaji. Menurut Steven (1958) yang telah menyatakan bahawa sebelum menjalankan kajian di kawasan kajian yang telah dipilih, borang soal selidik telah melalu satu proses kesahan pakar. Seramai lima orang pakar telah mengesahkan borang soal selidik yang akan digunakan dalam kajian ini. Pakar-pakar tersebut merupakan guru-guru yang mempunyai pengalaman mengajar selama 20 tahun dalam mengajar Kesusasteraan Melayu Komunikatif di beberapa buah sekolah menengah. Guru-guru tersebut ialah Cikgu Ahmad Yani yang merupakan guru dari Kelantan, Cikgu Abang Musa, Cikgu Anthony Tutong, Cikgu Carolinelyn Jerry dan Cikgu Rosnah.

\begin{tabular}{|c|c|c|c|c|c|c|}
\hline Tema/Unit & Penilai 1 & Penilai 2 & Penilai 3 & Penilai 4 & Penilai 5 & $\begin{array}{c}\text { Nilai Persetujuan } \\
\text { Keseluruhan }\end{array}$ \\
\hline $\begin{array}{c}\text { Prinsip } \\
\text { Pembelajaran } \\
\text { Mentalis }\end{array}$ & $\begin{array}{c}\mathrm{K}= \\
\frac{f a-f c}{N-f c} \\
=\frac{29-18}{36-18} \\
=0.61\end{array}$ & $\begin{array}{c}\mathrm{K}= \\
\frac{f a-f c}{N-f c} \\
=\frac{35-18}{36-18} \\
=0.94\end{array}$ & $\begin{array}{c}\mathrm{K}= \\
\frac{f a-f c}{N-f c} \\
=\frac{35-18}{36-18} \\
=0.94\end{array}$ & $\begin{array}{c}\mathrm{K}= \\
\frac{f a-f c}{N-f c} \\
=\frac{30-18}{36-18} \\
=0.67\end{array}$ & $\begin{array}{c}\mathrm{K}= \\
\frac{f a-f c}{N-f c} \\
=\frac{32-18}{36-18} \\
=0.78\end{array}$ & $\begin{array}{c}\mathrm{K}=\frac{0.61+0.94+0.94+0.67+0.78}{5} \\
=0.788 \\
=0.79\end{array}$ \\
\hline
\end{tabular}

\section{DAPATAN KAJIAN}

\section{Analisis Deskriptif}

\section{Demografi Responden}

Jadual 1 menunjukkan penggunaan Skala Likert hasil dapatan kajian mengenai taburan demografi responden. Daripada 200 jumlah responden, pelajar Tingkatan 4 mencatat jumlah responden yang paling tinggi dengan seramai 118 orang $(59.0 \%)$, diikuti dengan jumlah responden pelajar Tingkatan 6 seramai 82 orang $(41.0 \%)$. Bagi kategori jantina, pelajar perempuan mencata jumlah yang tinggi iaitu seramai $124(62.0 \%)$ orang responden manakala seramai $76(38.0 \%)$ orang responden adalah lelaki. Bagi kategori bangsa pula, jumlah bangsa tertinggi seramai $88(44.0 \%)$ orang pelajar adalah berbangsa Melayu diikuti dengan bangsa Bidayuh seramai 59 (29.5\%) orang responden, Iban 29 (14.5\%) orang responden. Responden Cina mencatat jumlah yang paling sedikit iaitu seramai 21 $(10.5 \%)$. Bagi kategori agama pula, agama yang mencatat kekerapan yang tinggi adalah agama Islam dengan jumlah responden seramai 95 (47.5\%) orang. Manakala agama Kristian seramai 87 (43.5\%) orang, agama Buddha 11 (5.5\%) orang responden dan yang paling sedikit agama Bahai seramai 4 $(2.0 \%)$ orang responden. 
JADUAL 1: Taburan Demografi Responden

\begin{tabular}{llrr}
\hline Pemboleh Ubah & Kategori & Kekerapan & Peratus (\%) \\
\hline Tingkatan & Tingkatan 4 & 118 & 59.0 \\
& Tingkatan 6 & 82 & 41.0 \\
Jantina & Lelaki & 76 & 38.0 \\
& Perempuan & 124 & 62.0 \\
Bangsa & Melayu & 88 & 44.0 \\
& Cina & 21 & 10.5 \\
& Iban & 29 & 14.5 \\
& Bidayuh & 59 & 29.5 \\
Agama & Islam & 95 & 47.5 \\
& Buddha & 11 & 5.5 \\
& Kristian & 87 & 43.5 \\
& Bahai & 4 & 2.0 \\
\hline
\end{tabular}

\section{Analisis Item aktiviti Mental}

Jadual 2 menunjukan analisis kekerapan bagi setiap item aktiviti mental. Skor min yang tertinggi adalah bagi kenyataan "Apakah medium yang guru gunakan untuk mewujudkan pembelajaran menyeronokkan dalam pengajaran Kesusasteraan Melayu?" iaitu $(\mathrm{m}=4.93$, sisihan piawai 1.94). Hal ini menunjukan bahawa medium yang digunakan oleh guru boleh mewujudkan suasana pembelajaran yang lebih menyeronokkan. Manakala min terendah adalah kenyataan "Aktiviti main peranan meningkatkan kefahaman pelajar" dengan kutipan nilai $(\mathrm{m}=4.22$, sisihan piawaian=1.88). Hal ini mungkin berlaku kerana tidak semua pelajar mahu menjalankan aktiviti main peranan ketika proses pengajaran dan pembelajaran berlaku. Namun begitu min ini masih diklasifikasikan sebagai min tinggi sekaligus menunjukkan bahawa responden bersetuju dengan aktiviti mental membantu dalam proses pengajaran dan pembelajaran. Kenyataan "Adakah aktiviti pengajaran dan pembelajaran Kesusasteraan melayu dalam kelas menarik minat pelajar" mencatat nilai min (4.41, sisihan paiwaian=1.94) dan diikuti dengan kenyataan "Pelajar akan mudah memahami sekiranya aktiviti dijalankan oleh guru" dengan nilai $\min (\mathrm{m}=4.40$, sisihan piawaian=1.82). Bagi kenyaatan "Aktiviti sumbang saran menggalakan pelajar berfikir secara kreatif" mencatat nilai min $(\mathrm{m}=4.79$, sisihan piawai=1.94) manakala kenyataan "Teknik pembelajaran yang berpusatkan kepada pelajar seperti main peranan, dan bacaan nyaring menarik minat pelajar" mencatat nilai min $(\mathrm{m}=4.57$, sisihan piawai $=1.89$ ).

JADUAL 2: Analisis Item Aktiviti Mental

\begin{tabular}{lcc}
\hline \multicolumn{1}{c}{ Kenyataan } & Min & $\begin{array}{c}\text { Sisihan } \\
\text { Piawai }\end{array}$ \\
\hline 1) Aktiviti main peranan meningkatkan kefahaman pelajar. & 4.22 & 1.88 \\
2) Adakah aktiviti pengajaran dan pembelajaran Kesusasteraan & 4.41 & 1.94 \\
$\quad \begin{array}{l}\text { Melayu dalam kelas menarik minat pelajar. } \\
\text { 3) Pelajar akan mudah memahami sekiranya aktiviti dijalankan oleh }\end{array}$ & 4.40 & 1.82 \\
guru. & 4.79 & 1.93 \\
4) Aktiviti sumbang saran menggalakan pelajar berfikir secara kreatif. & 4.93 & 1.94 \\
5) Apakah medium yang guru gunakan untuk mewujudkan \\
$\begin{array}{l}\text { pembelajaran menyeronokkan dalam pengajaran Kesusasteraan } \\
\text { Melayu? }\end{array}$ & 4.57 & 1.89 \\
\hline $\begin{array}{l}\text { Teknik penbelajaran yang berpusatkan kepada pelajar seperti main } \\
\text { peranan, dan bacaan nyaring menarik minat pelajar. }\end{array}$ & & \\
\hline
\end{tabular}

Analisis Item Menegaskan Makna 
Jadual 3 menunjukan analisis deskriptif skor min dan sisihan piawaian bagi item menegaskan makna. Kenyataan "Pelajar dapat memahami penggunaan ayat gramatis dalam ayat" mencatat nilai min tertinggi bagi nilai kepuasan diri dengan bacaan $(m=5.21$, sisihan piawaian=1.97). Hal ini menunjukan penggunaan ayat gramatis memain peranan untuk menarik minat pelajar. Manakala kenyataan "Penekanan yang diberikan oleh guru kepada pelajar dalam memahami penggunaan bahasa dapat difahami" pula mencatat min terendah iaitu dengan bacaan min $(\mathrm{m}=3.35$, sisihan piawaian=2.10). Namun nilai min masih lagi diklasifikasikan sebagai min tinggi dan mungkin penekanan yang diberikan oleh guru turut membantu sedikit sebanyak dalam proses pembelajaran dan pengajaran. Kenyataan "Elemen sastera dapat meningkatkan penguasaan bahasa" mencatat nilai $\min (\mathrm{m}=3.56$, sisihan piawaian=2.12. Seterusnya kenyataan "Kefahaman struktur bahasa dapat meningkatkan pengetahuan pelajar" mencatat nilai $\min (\mathrm{m}=3.85$, sisihan piawaian=1.93) manakala kenyataan "Mata pelajaran Kesusasteraan Melayu dapat digunakan membantu pelajar memahami bahasa yang digunakan dalam teks" mencatat nilai $\min (\mathrm{m}=4.57$, sisihan piawaian $=1.99)$. Seterusnya kenyataan "Pelajar dapat menguasai bahasa yang terdapat dalam Kesusasteraan Melayu" mencatat nilai $\min (\mathrm{m}=5.05$, sisihan piawaian $=1.89)$.

JADUAL 3: Analisis Item Menegaskan Makna

\begin{tabular}{lcc}
\hline \multicolumn{1}{c}{ Kenyataan } & Min & $\begin{array}{c}\text { Sisihan } \\
\text { Piawai }\end{array}$ \\
\hline 1) Pelajar dapat memahami penggunaan ayat gramatis dalam ayat & 5.21 & 1.97 \\
2) Pelajar dapat menguasai bahasa yang terdapat dalam Kesusasteraan & 5.05 & 1.89 \\
$\begin{array}{l}\text { Melayu. } \\
\text { 3) Mata pelajaran Kesusasteraan Melayu dapat digunakan membantu }\end{array}$ & 4.57 & 1.99 \\
$\begin{array}{l}\text { pelajar memahami bahasa yang digunakan dalam teks. } \\
\text { 4) Kefahaman struktur bahasa dapat meningkatkan pengetahuan pelajar. }\end{array}$ & 3.85 & 1.93 \\
5) Penekanan yang diberikan oleh guru kepada pelajar dalam memahami & 3.55 & 2.10 \\
$\begin{array}{l}\text { penggunaan bahasa dapat difahami. } \\
\text { 6) Elemen sastera dapat meningkatkan penguasaan bahasa. }\end{array}$ & 3.56 & 2.12 \\
\hline
\end{tabular}

\section{Analisis Item Mencerna Idea}

Jadual 4 menunjukan analisis deskritif skor min dan sisihan piawaian bagi item nilai pencapaian prestasi diri. Kenyataan "Pelajar dapat membentuk ayat yang gramatis semasa pengajaran dan pembelajaran kesusasteraan Melayu." mencatat nilai min tertinggi bagi nilai kepuasan diri dengan bacaan $(\mathrm{m}=4.57$, sisihan piawaian=2.01). Manakala kenyataan "Pelajar yang pasif akan menjadi pelajar yang aktif di dalam kelas" pula mencatat min terendah iaitu dengan bacaan $\min (\mathrm{m}=3.99$, sisihan piawaian=.1.81). Namun nilai min masih lagi diklasifikasikan sebagai min tinggi. Kenyataan "Pelajar dapat mengeluar idea semasa pengajaran dan pembelajaran" mencatat nilai min $(\mathrm{m}=4.30$, sisihan piawaian=1.87). Seterusnya kenyataan "Masalah dapat diselesaikan secara individu" mencatat nilai $\min (\mathrm{m}=4.17$, sisihan piawaian=1.88), kenyataan "Pelajar mempunyai kemampuan untuk menyelesaikan masalah secara berkumpulan mencatat nilai $\min (\mathrm{m}=4.41$, sisihan piawaian= 1.99) manakala kenyataan "Pelajar yang pasif akan menjadi pelajar yang aktif di dalam kelas" mencatat nilai $\min (\mathrm{m}=3.99$, sisihan piawaian $=1.81)$.

JADUAL 4: Analisis Item Mencerna Idea

\begin{tabular}{lrr}
\hline \multicolumn{1}{c}{ Kenyataan } & Min & $\begin{array}{c}\text { Sisihan } \\
\text { Piawai }\end{array}$ \\
\hline 1) Pelajar dapat membentuk ayat yang gramatis semasa pengajaran dan pembelajaran & 4.57 & 2.01 \\
$\quad \begin{array}{l}\text { Kesusasteraan Melayu. } \\
\text { 2) Pelajar dapat menyelesaikan masalah iaitu menyelesaikan soalan yang diberikan oleh } \\
\quad \text { guru. }\end{array}$ & 4.40 & 1.93 \\
3) Pelajar dapat mengeluar idea semasa pengajaran dan pembelajaran. & 4.30 & 1.87 \\
a) Masalah dapat diselesaikan secara individu. & 4.17 & 1.88 \\
5) Pelajar yang pasif akan menjadi pelajar yang aktif di dalam kelas. & 3.99 & 1.81
\end{tabular}




\section{Analisis Item Struktur}

Jadual 5 menunjukkan analisis kekerapan bagi setiap item nilai kegembiraan. Skor min yang tertinggi adalah bagi kenyataan "Pelajar dapat memberi contoh berdasarkan soalan yang diberikan oleh guru" iaitu $(\mathrm{m}=4.56$, sisihan piawaian=1.83). Manakala min yang terendah adalah kenyataan "Latihan yang diberikan dapat membantu pelajar dalam memahami Kesusasteraan Melayu" dengan kutipan nilai $(\mathrm{m}=3.45$, sisihan piawaian=1.86). Namun begitu nilai min masih diklasifikasikan sebagai min tinggi. Kenyataan "Pelajar dapat meningkatkan pengetahuan pelajar" mencatat nilai min $(\mathrm{m}=4.21$, sisihan piawaian=1.86), kenyataan "Pelajar dapat menghuraikan soalan yang diberikan oleh guru" mencatat nilai min $(\mathrm{m}=4.20$, sisihan piawaian=1.85) dan dikuti dengan kenyataan "Pembentukan ayat gramatis meningkatkan pengetahuan pelajar" dengan nilai min $(\mathrm{m}=4.10$, sisihan piawaian=1.8). Bagi kenyataan "Guru sering kali memberi latihan kepada pelajar" mencatat nilai $\min (\mathrm{m}=3.48$, sisihan piawaian $=1.81)$.

JADUAL 5: Analisis Item Struktur

\begin{tabular}{lrr}
\hline \multicolumn{1}{c}{ Kenyataan } & Min & Sisihan Piawai \\
\hline 1) Guru sering kali memberi latihan kepada pelajar. & 3.48 & 1.81 \\
2) Latihan yang diberikan dapat membantu pelajar dalam memahami Kesusasteraan & 3.45 & 1.86 \\
Melayu. & 4.21 & 1.86 \\
3) Pelajar dapat meningkatkan pengetahuan pelajar & 4.20 & 1.85 \\
4) Pelajar dapat menghuraikan soalan yang diberikan oleh guru. & 4.56 & 1.93 \\
5) Pelajar dapat memberi contoh berdasarkan soalan yang diberikan oleh guru. & 4.10 & 1.82 \\
6) Pembentukan ayat gramatis meningkatkan pengetahuan pelajar. & & \\
\hline
\end{tabular}

\section{Analisis Item Sintaksis atau Morfologi}

Jadual 6 menunjukan analisis deskritif skor min dan sisihan piawaian bagi item nilai rasa selamat. Kenyataan "Pelajar dapat menambah kosa kata dalam pengajaran sastera" mencatat nilai min tertinggi bagi nilai kepuasan diri dengan bacaan $(\mathrm{m}=3.88$, sisihan piawaian=1.97). Manakala kenyataan "Pelajar mempelajari mengolah ayat gramatis" pula mencatat min terendah iaitu dengan bacaan min $(\mathrm{m}=3.19$, sisihan piawaian=1.71). Kenyataan "Penggunaan bahasa sastera dalam pengajaran binaan ayat Bahasa Melayu dapat meningkatkan kefahaman pelajar" dan kenyataan "Pelajar dapat membina ayat gramatis dalam ayat" masing-masing mencatat nilai min $(\mathrm{m}=3.33$, sisihan piawaian=1.90). Seterusnya kenyataan "Saya percaya dengan pembelian produk pencerahan di internet" mencatat nilai min $(\mathrm{m}=3.57$, sisihan piawaian=2.01) manakala kenyataan "Dalam mata pelajaran Kesusateraan Melayu mempunyai penggunaan pola ayat bahasa Melayu." mencatat nilai $\min (\mathrm{m}=3.20$, sisihan piawaian $=1.77)$.

JADUAL 6: Analisis Item Sintaksis atau Morfologi

\begin{tabular}{lcc}
\hline \multicolumn{1}{c}{ Kenyataan } & Min & $\begin{array}{c}\text { Sisihan } \\
\text { Piawai }\end{array}$ \\
\hline 1) Penggunaan bahasa sastera dalam pengajaran binaan ayat bahasa & 3.33 & 1.90 \\
Melayu dapat meningkatkan kefahaman pelajar. & 3.57 & 2.01 \\
2) Pelajar memahami dan membina ayat-ayat dengan aspek sastera. & 3.33 & 1.90 \\
3) Pelajar dapat membina ayat gramatis dalam ayat. & 3.19 & 1.71 \\
4) Pelajar mempelajari mengolah ayat gramatis. & 3.88 & 1.97 \\
5) Pelajar dapat menambah kosa kata dalam pengajaran sastera. & 3.20 & 1.77 \\
6) Dalam mata pelajaran Kesusateraan Melayu mempunyai penggunaan & & \\
\hline
\end{tabular}




\section{Analisis Item Kesalahan Ambil Kira}

Jadual 7 menunjukan analisis deskritif skor min dan sisihan piawaian bagi item nilai kepunyaan. Kenyataan "Pelajar menunjukan kebolehan mereka kepada guru" mencatat nilai min tertinggi bagi nilai kepuasan diri dengan bacaan $(\mathrm{m}=4.05$, sisihan piawaian=2.01). Manakala kenyataan "Guru membantu pelajar yang lemah dalam mata pelajaran kesusateraan melayu" pula mencatat min terendah iaitu dengan bacaan min $(m=3.68$, sisihan piawaian=1.85). Kenyataan "Guru menyedari kelemahan pelajar" mencatat nilai $\min (\mathrm{m}=3.84$, sisihan piawaian $=2.14)$ dan dikuti dengan kenyataan "Pelajar boleh mengulang kembali apa yang disampaikan oleh guru secara tepat" dengan nilai $\min (\mathrm{m}=3.85$, sisihan piawaian=2.07). Bagi kenyataan "Pelajar memperbaiki kelemahan mereka yang telah diperbetulkan oleh guru" mencatat nilai $\min (\mathrm{m}=3.90$, sisihan piawaian=2.11) dan kenyataan "Guru membetulkan kesalahan yang dilakukan oleh pelajar" mencatat nilai $\min (\mathrm{m}=3.95$, sisihan piawaian=2.07).

JADUAL 7: Analisis Item Kesalahan Ambil Kira

\begin{tabular}{lcr}
\hline Kenyataan & Min & Sisihan Piawai \\
\hline 1) Pelajar boleh mengulang kembali apa yang disampaikan oleh guru secara tepat. & 3.85 & 2.07 \\
2) Guru menyedari kelemahan pelajar. & 3.84 & 2.14 \\
3) Guru membantu pelajar yang lemah dalam mata pelajaran Kesusateraan Melayu. & 3.68 & 1.85 \\
4) Pelajar menunjukan kebolehan mereka kepada guru. & 4.05 & 2.01 \\
5) Guru membetulkan kesalahan yang dilakukan oleh pelajar. & 3.95 & 2.07 \\
6) Pelajar memperbaiki kelemahan mereka yang telah diperbetulkan oleh guru. & 3.90 & 2.11 \\
\hline
\end{tabular}

\section{Analisis Inferensi}

\section{Analisis Ujian Korelasi Pearson}

Melalui ujian Korelasi Pearson ini, terdapat enam hipotesis yang dikaji berdasarkan kepada kesemua pemboleh ubah yang terlibat. Ujian ini dilakukan untuk mengenal pasti hubungan yang signifikan antara kesemua pemboleh ubah yang terlibat.

\section{Hubungan antara Aktiviti Mental dan Pemahaman Teks Kesusasteraan Melayu}

HA Terdapat hubungan yang signifikan antara aktiviti mental dan pemahaman teks Kesusateraan Melayu.

Ho Tidak terdapat hubungan yang signifikan antara aktiviti mental dan pemahaman teks Kesusateraan Melayu.

Berdasarkan jadual 8 menunjukan hubungan antara aktiviti mental dan pemahaman teks Kesusasteraan Melayu yang dikaji dengan menggunakan Pekali Korelasi Pearson. Hasil dapatan menunjukan wujud hubungan yang signifikan antara kedua-dua pemboleh ubah $(\mathrm{r}=.433, \mathrm{n}=200$, $\mathrm{p}=.000$ ). Nilai pekali korelasi menunjukan hubungan sederhana tinggi antara item aktiviti mental dengan pemahaman teks Kesusasteraan Melayu. Hal ini menurut Goerge \& Mallery (2006) nilai pekali korelasi antara 0.30-0.49 adalah sederhana tinggi. Jesteru itu HA diterima.

JADUAL 8: Hubungan antara aktiviti mental dengan pemahaman teks Kesusateraan Melayu

\begin{tabular}{|c|c|c|c|}
\hline Pemboleh Ubah & \multicolumn{2}{|c|}{ Pemahaman Teks Kesusasteraan Melayu } & Tahap Hubungan \\
\hline & Sig. & $\mathrm{N}$ & \\
\hline Aktiviti Mental & $.433^{* *}$ & 200 & Sederhana Tinggi \\
\hline
\end{tabular}

Signifikan pada aras $\mathrm{p}<0.05$

\section{Hubungan antara Menegaskan Makna dengan Pemahaman Teks Kesusasteraan Melayu}

HA Terdapat hubungan yang signifikan antara item menegaskan Makna dan Pemahaman Teks 
Kesusasteraan Melayu.

HO Tidak terdapat hubungan yang signifikan antara item menegaskan Makna dan Pemahaman teks Kesusasteraan Melayu.

Berdasarkan jadual 9 menunjukan hubungan antara item menegaskan makna dengan pemahaman teks Kesusasteraan Melayu yang di uji dengan menggunakan pekali korelasi Pearson. Hasil dapatan menunjukan wujud hubungan yang signifikan antara kedua-dua pemboleh ubah $(\mathrm{r}=187, \mathrm{n}=200$, $\mathrm{p}=.008$ ). Nilai pekali korelasi menunjukan hubungan yang rendah antara item menegaskan makna dan pemahaman teks Kesusasteraan Melayu namun masih mempunyai hubungan. Menurut Goerge \& Mallery (2006) nilai pekali korelasi antara 0.10-0.29 adalah rendah. Jesteru HA diterima.

JADUAL 9: Hubungan antara item menegaskan makna dengan pemahaman teks Kesusasteraan Melayu

\begin{tabular}{|c|c|c|c|}
\hline Pemboleh Ubah & Pemahaman Teks K & Ielayu & Tahap Hubungan \\
\hline & Sig. & $\mathrm{N}$ & \\
\hline Menegaskan Makna & $.187 * *$ & 200 & Rendah \\
\hline
\end{tabular}

Signifikan pada aras $\mathrm{p}<0.05$

\section{Hubungan antara Item Mencerna Idea dan Pemahaman Teks Kesusasteraan Melayu}

HA Terdapat Hubungan yang signifikan antara item mencerna idea dan pemahaman teks Kesusasteraan Melayu

HO Tidak terdapat Hubungan yang signifikan antara item mencerna idea dan pemahaman teks Kesusasteraan Melayu

Berdasarkan jadual 10 menunjukan hubungan antara item mencerna idea dengan pemahaman teks Kesusasteraan Melayu yang dikaji dengan menggunakan Pekali Korelasi Pearson. Hasil dapatan menunjukan wujud hubungan yang signifikan antara kedua-dua pembolehubah $(\mathrm{r}=.711, \mathrm{n}=200$, $\mathrm{p}=.000$ ). Nilai pekali korelasi menunjukan hubungan yang tinggi antara item mencerna idea dan pemahaman teks Kesusasteraan Melayu. Hal ini kerana menurut Goeorge \& Mallery (2006) nilai pekali korelasi antara 0.71-0.90 adalah tinggi. Justeru $\mathrm{H}_{\mathrm{A}}$ diterima.

JADUAL 10: Hubungan antara item mencerna idea dengan pemahaman teks Kesusasteraan Melayu

\begin{tabular}{|c|c|c|c|}
\hline Pemboleh Ubah & Pemahaman Teks K & Ielayu & Tahap Hubungan \\
\hline & Sig. & $\mathrm{N}$ & \\
\hline Mencerna Idea & $.711 * *$ & 200 & Tinggi \\
\hline
\end{tabular}

Signifikan pada aras $\mathrm{p}<0.05$

\section{Hubungan Di Antara Item Struktur Dan Pemahaman Teks Kesusasteraan Melayu}

$\mathrm{H}_{\mathrm{A}}$ Terdapat Hubungan yang signifikan antara item struktur dan pemahaman teks Kesusasteraan Melayu.

Ho Tidak terdapat Hubungan yang signifikan antara item struktur dan pemahaman teks Kesusasteraan Melayu.

Berdasarkan jadual 11 menunjukan hubungan di antara item struktur dengan pemahaman teks Kesusateraan Melayu yang dikaji dengan menggunakan Pekali Korelasi Pearson. Hasil dapatan menunjukan wujud hubungan yang signifikan antara kedua-dua pemboleh ubah $(\mathrm{r}=.430, \mathrm{n}=200$, $\mathrm{p}=.000$ ). Nilai pekali korelasi menunjukan hubungan sederhana tinggi antara item struktur dan pemahaman teks Kesusasteraan Melayu. Hal ini kerana menurut Goerge \& Mallery (2006) nilai pekali korelasi antara 0.30-0.49 adalah sederhana tinggi. Justeru $\mathrm{H}_{\mathrm{A}}$ diterima.

JADUAL 11: Hubungan antara item struktur dengan pemahaman teks Kesusasteraan Melayu. 


\begin{tabular}{|c|c|c|c|}
\hline Pemboleh Ubah & Pemahaman Teks & Telayu & Tahap Hubungan \\
\hline & Sig. & $\mathrm{N}$ & \\
\hline Struktur & $.430 * *$ & 200 & Sederhana Tinggi \\
\hline
\end{tabular}

Signifikan pada aras $\mathrm{p}<0.05$

\section{Hubungan antara Item Sintaksis atau Morfologi dan Pemahaman Teks Kesusasteraan Melayu}

$\mathrm{H}_{\mathrm{A}}$ Terdapat hubungan yang signifikan antara item sintaksis atau morfologi dan pemahaman teks Kesusasteraan Melayu.

$\mathrm{H}_{\mathrm{O}}$ Tidak terdapat hubungan yang signifikan antara item sintaksis atau morfologi dan pemahaman teks Kesusasteraan Melayu.

Jadual 12 menunjukan hubungan antara item sintaksis atau morfologi dengan pemahaman teks Kesusasteraan Melayu yang dikaji menggunakan Pekali Korelasi Pearson. Hasil dapatan kajian menunjukan wujud hubungan yang signifikan antara kedua-dua pemboleh ubah $(r=704, n=200$, $\mathrm{p}=.000$ ). Nilai pekali korelasi menunjukan hubungan yang tinggi antara item sintaksis atau morfologi dengan pemahaman teks Kesusasteraan Melayu. Hal ini kerana menurut Goerge \& Mallery (2006) nilai pekali korelasi antara 0.71-0.90 adalah tinggi. Justeru itu $\mathrm{H}_{\mathrm{A}}$ diterima.

JADUAL 12: Hubungan antara item sintaksis atau morfologi dengan pemahaman teks Kesusasteraan Melayu

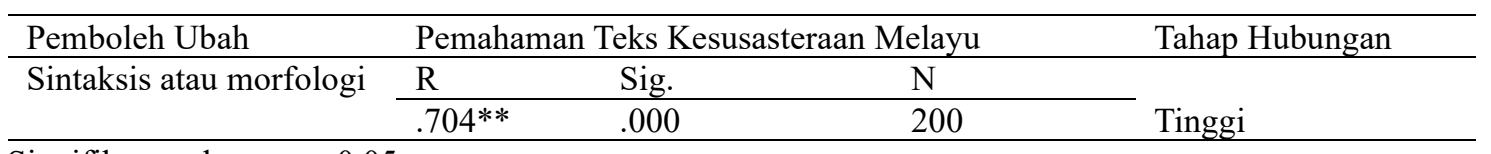

Signifikan pada aras $\mathrm{p}<0.05$

\section{Hubungan antara Item Kesalahan Ambil Kira dan Pemahaman Teks Kesusasteraan Melayu}

$\mathrm{H}_{\mathrm{A}}$ Terdapat hubungan yang signifikan antara item kesalahan ambil kira dan pemahaman teks Kesusasteraan Melayu

Ho Tidak terdapat hubungan yang signifikan antara item kesalahan ambil kira dan pemahaman teks Kesusasteraan Melayu

Berdasarkan jadual 13 menunjukan hubungan antara item kesalahan ambil kira dengan pemahaman teks Kesusasteraan Melayu yang dikaji menggunakan Pekali Korelasi Pearson. Hasil dapatan kajian menunjukan wujud hubungan yang signifikan di antara kedua-dua pemboleh ubah $(r=.330, n=200$, $\mathrm{p}=.000$ ). Nilai pekali korelasi menunjukan hubungan yang sederhana tinggi antara item sintaksis atau morfologi dengan pemahaman teks Kesusasteraan Melayu. Hal ini kerana menurut Goerge \& Mallery (2006) nilai pekali korelasi antara 0.30-0.49 adalah sederhana tinggi. Justeru itu $\mathrm{H}_{\mathrm{A}}$ diterima.

JADUAL 13: Hubungan antara item kesalahan ambil kira dengan pemahaman teks kesusasteraan Melayu

\begin{tabular}{|c|c|c|c|}
\hline \multirow{3}{*}{$\begin{array}{l}\text { Pemboleh Ubah } \\
\text { Kesalahan Ambil Kira }\end{array}$} & Pemahaman Teks K & Gelayu & Tahap Hubungan \\
\hline & Sig. & $\mathrm{N}$ & \multirow[b]{2}{*}{ Sederh } \\
\hline & $.430 * *$ & 200 & \\
\hline
\end{tabular}

Signifikan pada aras $\mathrm{p}<0.05$

Hasil daripada ujian Korelasi Pearson ini guru dapat menentukan kemahiran bahasa yang perlu diajar, mereka perlulah terlebih dahulu mengetahui peringkat dan tahap pengetahuan bahasa yang telah diperoleh dan dikuasai oleh pelajar tersebut. Secara perlahan pelajar akan terlibat aktif dalam proses pembelajaran dalam bilik darjah bersama guru. Hal ini termasuklah tindak balas pelajar terhadap soalan-soalan yang diberikan oleh guru semasa sesi pengajaran dan pembelajaran guru yang mengajar Kesusasteraan Melayu. Guru akan dapat mengenal pasti kaedah pengajaran yang paling berkesan untuk pengajaran dan pembelajaran pelajar dalam kelas untuk mata pelajaran Kesusasteraan Melayu. 


\section{Kesahan dan Kebolehpercayaan Cohen Kappa}

JADUAL 14: Skala Persetujuan Cohen Kappa

\begin{tabular}{cc}
\hline Nilai Kappa & Skala Persetujuan \\
\hline Bawah 0.00 & Sangat lemah \\
$\mathbf{0 . 0 0}-\mathbf{0 . 2 0}$ & Lemah \\
$\mathbf{0 . 2 1}-\mathbf{0 . 4 0}$ & Sederhana Lemah \\
$\mathbf{0 . 4 1}-\mathbf{0 . 6 0}$ & Sederhana \\
$\mathbf{0 . 6 1}-\mathbf{0 . 8 0}$ & Baik \\
$\mathbf{0 . 8 1}-\mathbf{1 . 0 0}$ & Sangat baik \\
\hline
\end{tabular}

Sumber: Fraenkel, Walled and Hyun (2012)

JADUAL 15: Nilai Persetujuan antara Pakar Penilai

\begin{tabular}{|c|c|c|c|c|c|c|}
\hline Tema/Unit & Penilai 1 & Penilai 2 & Penilai 3 & Penilai 4 & Penilai 5 & $\begin{array}{c}\text { Nilai Persetujuan } \\
\text { Keseluruhan }\end{array}$ \\
\hline $\begin{array}{c}\text { Prinsip } \\
\text { Pembelajaran } \\
\text { Mentalis }\end{array}$ & $\begin{aligned} \mathrm{K} & =\frac{f a-f c}{N-f c} \\
& =\frac{29-18}{36-18} \\
& =0.61\end{aligned}$ & $\begin{aligned} \mathrm{K} & =\frac{f a-f c}{N-f c} \\
& =\frac{35-18}{36-18} \\
& =0.94\end{aligned}$ & $\begin{aligned} \mathrm{K} & =\frac{f a-f c}{N-f c} \\
& =\frac{35-18}{36-18} \\
& =0.94\end{aligned}$ & $\begin{aligned} \mathrm{K} & =\frac{f a-f c}{N-f c} \\
& =\frac{30-18}{36-18} \\
& =0.67\end{aligned}$ & $\begin{aligned} \mathrm{K} & =\frac{f a-f c}{N-f c} \\
& =\frac{32-18}{36-18} \\
& =0.78\end{aligned}$ & 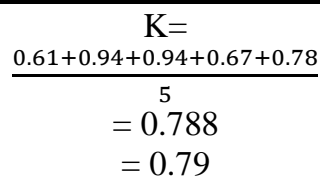 \\
\hline
\end{tabular}

\section{RUMUSAN}

Kesimpulannya, ujian dijalankan untuk menguji hubungan dan penggunaan item pemboleh ubah yang tidak bersandar kepada pemboleh ubah bersandar. Kajian meliputi analisis deskriptif dan analisis inferensi. Bagi analisis deskriptif, data telah dipersembahkan dalam bentuk peratusan dan min. Manakala bagi analisis inferensi pula, ujian korelasi Pearson dijalankan untuk melihat hubungan item yang digunakan. Persoalan kajian, hipotesis serta objektif kajian terjawab dengan ujian yang telah dijalankan. Analisis Cohen Kappa dapat membantu pengkaji mengenal pasti kebolehpercayaan data yang diperoleh daripada kajian. Dapatan keseluruhan hipotesis yang diuji, kesemua hipotesis telah diterima kerana terdapat hubungan yang signifikan antara kesemua pemboleh ubah yang diuji. Hasil daripada kajian ini juga, pelajar lebih aktif dan berfikir secara kritis semasa pengajaran dan pembelajaran Kesusasteraan Melayu. Mata pelajaran Kesusasteraan Melayu juga mudah diajar dengan penggunaan pelbagai kaedah kepada pelajar bagi memberi kefahaman pelajar dengan mengaplikasikan prinsip pembelajaran mentalis dalam pengajaran dan pembelajaran. Para pelajar dapat memupuk daya imaginasi yang tinggi dan secara tidak langsung mempengaruhi karakter seseorang pelajar dengan menggunakan prinsip pembelajaran mentalis.

\section{RUJUKAN}

Abdullah Yusof et al. (2009). Semantik dan Pragmatik Bahasa Melayu. Kuala Lumpur: Pustaka Salam Sdn. Bhd.

Abdul Halim Ali. (2006). Teori dan Kritikan Sastera Barat dan Malaysia. Tanjong Malim: Profesional Baharu. Abdul Halim Ali. (2006). Mendekati Puisi Melayu Tradisional. Tanjung Malim: Profesional Baharu.

Abd. Aziz Talib. (2000). Pedagogi Bahasa Melayu Prinsip, Kaedah dan Teknik. Kuala Lumpur: Utusan Publication \& Distributors Sdn. Bhd. 
Abdul Rahman Abdul Majid Md Idris. (2012). Teori Falsafah Bahasa (Teori Rashid). Tanjong Malim: Penerbit UPSI.

Abdul Ghafar Md Din. (2003). Prinsip dan Amalan Pengajaran. Kuala Lumpur: Utusan Publication \& Distributors Sdn. Bhd.

Ahmad Khair Mohd Nor. (2003). Pengantar Sintaksis Bahasa Melayu. Kuala Lumpur: Utusan Publication \& Distributor.

Anita Woolfolk, Anita Woolfolk Hoy \& Lorraine McCune-Nicolich. (1980). Educational Psychology for Teachers. Universiti Minnesoto: Prentice-Hall.

Ariff Mohemad et al. (2009). Kesusasteraan dalam Pengajaran Bahasa Melayu. Kuala Lumpur Pustaka Salam Sdn. Bhd.

Asmah Omar. (1984). Kaedah Pengajaran Bahasa. Kuala Lumpur: Dewan Bahasa dan Pustaka.

Asmah Omar. (1992). Kajian Perkembangan Bahasa Melayu. Kuala Lumpur: Dewan Bahasa dan Pustaka.

Bloomfield, L. (1933). Language. New Jersey: Holt, Rinehart \& Winston.

Bloom. B. (1964). Stability and Change in Human Characteristics. New York: Wiley.

F.R Palmer. (1992). Semantik. Kuala Lumpur: Dewan Bahasa dan Pustaka (Penterjemah: Prof. Abdullah Hassan).

Fraenkel, J.R Wallen et al. (2012). How to Design and Evaluate Research In Education $8^{\text {th }}$ ed) New York: Mc Graw Hill.

H.W Fowler \& F.G Fowler. (1964). The Concise Oxford Dictionary of Current English. Oxford: Clarendon Press.

Juriah Long et al. (1990). Pengkaedahan Pengajaran Bahasa Melayu. Petaling Jaya: Fajar Bakti.

Kamaruddin Hj. Husin et al. (2004). Pedagogi Asas Pendidikan. Kuala Lumpur: Kayazanu Enterprise.

Kamaruddin Hj Husin et al. (2011). Pedagogi Bahasa Amalan Bilik Darjah. Perak: Emeritus Publications .

Kamarudin Hj. Husin. (1990). Pengajaran dan Pembelajaran Lisan. Kuala Lumpur: Dewan Bahasa dan Pustaka.

Kamarudin Hj. Husin. (1998). Pedagogi Bahasa, Perkaedahan. Kuala Lumpur: Budiman Sdn. Bhd.

Kamarudin Hj. Husin. (1986). Kaedah Pengajaran dan Pembelajaran Bahasa. Selangor: Sarjana M) Sdn. Bhd.

Knapton. J. (1967). Teaching A Literature-Centered English Programme. New York: Random House.

Karmiloff-Smith, A. (1986). Some Fundamental Aspects ff Language Development after Age 5. In. P. Fletcher $\&$ M. Garman (Eds) Language Acquisition $\left(2^{\text {nd }} E d\right)$. New York: Cambridge University Press.

Kamus Dewan. (2002). Edisi Ketiga. Kuala Lumpur: Dewan Bahasa dan Pustaka.

Lawton, Denis. (1973). Social Change Educational Theory and Curriculum Planning. Ken: Hudder and Stoughton Educational.

Mengantar Simanjuntak. (1987). Pengantar Psikolinguistik Moden. Kuala Lumpur: Dewan Bahasa dan Pustaka.

Mok Soon Sang. (1998). Pedagogi 3 Pengajian dan Penilaian, Pemulihan, Pengayaan dan Pendidikan Inkuiri. Kuala Lumpur: Kumpulan Budiman Sdn. Bhd.

Mok Soon Sang. (2010). Pedagogi Untuk Pengajaran dan Pembelajaran. Puchong: Multimedia Sdn. Bhd.

Mohd Majid Konting (2000). Kaedah Penyelidikan Pendidikan. Kuala Lumpur: Dewan Bahasa dan Pustaka.

Puteri Roslina Abdul Wahid. (2004). Bahasa Antara. Kuala Lumpur: Dewan Bahasa dan Pustaka.

Raminah Hj. Sabran dan Rahim Syam. (1985). Kajian Bahasa. Petaling Jaya: Fajar Bakti.

Rashidi Azizan dan Abdul Razak. (1995). Pengajaran dalam Bilik Darjah. Kaedah dan Strategi. Selangor: Mas Enterprise.

Rahil Mahyuddin et al. (2009). Amalan Pengajaran Berkesan. Selangor: Karisma Publications Sdn. Bhd.

Seri Lanang Jaya Haji Rohani. (1996). Orientasi Komunikatif dalam Pengajaran dan Pembelajaran Bahasa Melayu di Sekolah Rendah. Tesis Sarjana Pendidikan UKM.

Siti Hajar Abdul Aziz. (2009). Bahasa Melayu 11. Selangor: Oxford Fajar Sdn. Bhd.

Syed Ali Ashraf. (1989). Prinsip dan Kaedah Islam di Dalam Pengajaran Ilmu Kesusasteraan, Falsafah Kesusasteraan dan Seni Halus. Kuala Lumpur: Dewan Bahasa dan Pustaka.

Skinner, B.F. (1957). Verbal Behaviour. East Nprwalk: CT: Appleton - Century Crofts.

Vygotsky (1934) Thought and Language. MIT Press: Cambridge, Mass.

Woolfolk, A.E dan McCune Nicolica. (1980). Educational Psychology for Teachers. New Jersey: Prentice Hall.

Zamri Mahmod. (2007). Psikolinguistik dalam Pengajaran dan Pemerolehan Bahasa Pertama dan Kedua. Selangor: Karisma Publication Sdn. Bhd. 
Prinsip Pembelajaran Mentalis dalam Pengajaran dan Pembelajaran

Teks Kesusasteraan Melayu Sekolah Menengah 